\title{
Atmospheric boundary layer wind profile at a flat coastal site - wind speed lidar measurements and mesoscale modeling results
}

\author{
R. Floors ${ }^{1}$, E. Batchvarova ${ }^{1,2}$, S.-E. Gryning ${ }^{1}$, A. N. Hahmann ${ }^{1}$, A. Peña ${ }^{1}$, and T. Mikkelsen ${ }^{1}$ \\ ${ }^{1}$ Wind Energy Division, Ris $\varnothing$ National Laboratory for Sustainable Energy, Technical University of Denmark, \\ P.O. Box 49, 4000 Roskilde, Denmark \\ ${ }^{2}$ National Institute of Meteorology and Hydrology, Sofia 1784, Bulgaria
}

Received: 31 December 2010 - Revised: 18 May 2011 - Accepted: 19 May 2011 - Published: 31 May 2011

\begin{abstract}
Wind profiles up to $600 \mathrm{~m}$ height are investigated. Measurements of mean wind speed profiles were obtained from a novel wind lidar and compared to model simulations from a mesoscale model (WRFARW v3.1). It is found that WRF is able to predict the mean wind profile rather well and typically within $1-2 \mathrm{~m} \mathrm{~s}^{-1}$ to the individual measured values. WRF underpredicts the normalized wind profile, especially for stable conditions. The effect of baroclinicity on the upper part of the wind profile is discussed.
\end{abstract}

\section{Introduction}

The wind profile above the surface layer and up to a kilometre within the atmospheric boundary layer is presently a challenge for wind assessment studies and air pollution applications, as mean wind speed instruments with high resolution in time and space have been rarely available until recently. Previously, surface layer scaling was often used to compare observed and theoretical wind profiles (Holtslag, 1984) and more recently a mixing length approach has been compared with lidar and wind profiler measurements above the surface layer (Gryning et al., 2007; Peña et al., 2010; Gryning et al., 2011). However, commonly available mesoscale meteorological models seem to have difficulties predicting the mean wind profile accurately due to complex phenomena taking place in nature and not accounted for in the local scaling based ABL parameterization schemes (Draxl et al., 2010). Here we report our findings from two weeks, 15 to 30 September 2010, of novel observations of wind speed up to $600 \mathrm{~m}$ height at Høvsøre, Denmark. The study was carried out with a newly deployed pulsed wind lidar (Leosphere WLS70) and the measurements were compared with simulations of the Weather Research and Forecasting (WRF) model (Skamarock et al., 2008).

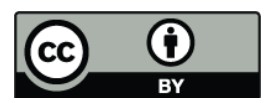

Correspondence to: R. Floors (rofl@ risoe.dtu.dk)

\section{Methods}

\subsection{Measurements}

The measurements were carried out at the National Test Station of Wind Turbines, which is located about $1.8 \mathrm{~km}$ east of the shoreline (for a map see Gryning et al., 2007). Except for the presence of the coastline, the terrain surrounding Høvsøre is very flat and homogeneous. It mainly consists of grass, crops and a few shrubs. On site, there is one dedicated meteorological mast of $116.5 \mathrm{~m}$ height and two light towers of $160 \mathrm{~m}$ height each. For the meteorological mast the wind speed is measured with Ris $\emptyset$ cup anemometers at nominal heights of $10,40,60,80,100,116.5 \mathrm{~m}$. The wind direction is measured with wind vanes at 10,60 and $100 \mathrm{~m}$. To extend the height range in which data are available, observations from the $160 \mathrm{~m}$ top level at the nearest light tower are also used. Both the light tower and the meteorological mast are equipped with METEK Scientific USA-1 sonic anemometers. These are installed at heights: 10, 20, 40, 60, 80, 100 and $160 \mathrm{~m}$. The sampling frequency of the sonic measurements is $20 \mathrm{~Hz}$. All sonic co-variances are based on 10-min averages of linearly de-trended time series. In addition, for extended height measurements, a pulsed wind lidar (WLS70) has been operating at the site since April 2010. The wind lidar measures wind speed and direction from $100 \mathrm{~m}$ above the ground and every $50 \mathrm{~m}$ up till 1 to $2 \mathrm{~km}$ height. The maximum measurement height is dependent on the attainable 10-min averaged Carrier to Noise (CNR) ratio. The upper 
measuring height is usually determined by the cloud base, where the lidar signal $(1.55 \mu \mathrm{m})$ largely weakens. The wind lidars Doppler shift based wind measurements are processed into 10-min average quantities. The wind lidar is equipped with a rotating silicon prism providing an optical scanning cone of 15 degrees. One 360 degree full scan (rotation) is performed about every $30 \mathrm{~s}$.

\subsection{WRF model description}

The wind profiles were predicted using a research real-time forecast system based on the WRF ARW model version 3.1 (Skamarock et al., 2008), developed by the National Centre for Atmospheric Research (NCAR). It is a numerical weather prediction and atmospheric simulation system designed for both research and operational applications. Here, a set up of three domains covering Northern Europe is used (for a map see Draxl et al. (2010)), with a horizontal grid size of 18,6 and $2 \mathrm{~km}$. Data for initial and boundary conditions comes from analyses and forecasts of the National Center for Environmental Prediction (NCEP, USA) global GFS model. The grid point from the $2 \mathrm{~km}$ resolution innermost grid at Høvsøre is located $700 \mathrm{~m}$ East and $2000 \mathrm{~m}$ North of the measuring point (mast and WLS70). The model calculates the meteorological parameters at 37 vertical levels from the surface to pressure level $100 \mathrm{hPa}$. Nine of these levels are within the height range of $600 \mathrm{~m}$ that is analysed in this study and the first model level is at $14 \mathrm{~m}$. The physical options of model setup include the Yonsei University (YSU) planetary boundary layer (PBL) scheme (Hong et al., 2006), the Noah land surface scheme (Chen and Dudhia, 2001) and the Thompson microphysics scheme (Thompson et al., 2004). A comparison with other PBL parameterizations can be found in Draxl et al. (2010). The YSU scheme is the one of the most commonly used parameterizations and we want to investigate its performance in predicting mean wind profiles for wind resource assessments. The model is run every $24 \mathrm{~h}$. After the $6 \mathrm{~h}$ spin-up of the model, the forecast up to $30 \mathrm{~h}$ is used to generate a continuous hourly time series.

\section{Results}

\subsection{Comparison between cup and wind lidar measurements}

The analysis of the measurements is limited to the period, 15 to 30 September 2010, because the lidar was running without many interruptions in this period. It constitutes a first analysis of the data in order to get an impression of the challenges and possibilities of wind profile lidar measurements and WRF wind simulations of up to several hundreds of meters. Firstly we evaluate the quality of the wind lidar measurements by comparing wind speed derived from the lidar to cup anemometer measurements at the meteorological mast at $100 \mathrm{~m}$ height, Fig. 1. The agreement can be seen to be good

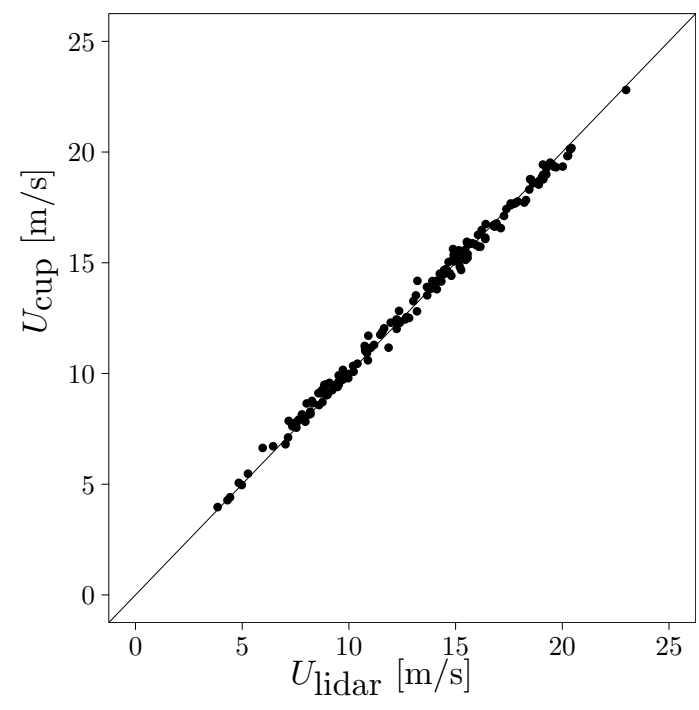

Figure 1. Comparison of wind speed measurements from the wind lidar and cup anemometer at $100 \mathrm{~m}$ height for $10 \mathrm{~min}$ means.

with a correlation coefficient $R^{2}=0.9995$ and gain of 0.9982 (through origo). It is clear from these data, that the WLS70 wind lidar is a precise remote sensing based tool for measurements of mean wind speed.

\subsection{Mean wind profile}

The wind speed at $100 \mathrm{~m}$ during the 2 week observation period is shown in Fig. 2 together with the prediction of the wind speed by the WRF model. It is a good period for model evaluation because of the considerable variation in the wind speed, from less than $2 \mathrm{~m} \mathrm{~s}^{-1}$ to more than $20 \mathrm{~m} \mathrm{~s}^{-1}$. It can be seen that the WRF model simulations predicts the variation of the wind speed relatively well, showing no obvious systematic deviation neither for small nor high wind speeds. The comparison is further illustrated at both 100 and $600 \mathrm{~m}$ height in scatter plots, Figs. 3 and 4, which indicates that the wind speed is slightly underpredicted by the WRF model at both $100 \mathrm{~m}$ and $600 \mathrm{~m}$ and typically is within $1-2 \mathrm{~m} \mathrm{~s}^{-1}$ of the individual measured values.

The normalized mean wind speed profile for the two week period is shown on Fig. 5. Each measurement of the wind speed is normalized with the sonic-anemometer measured friction velocity at $20 \mathrm{~m}$ height and then all normalized wind speeds are averaged. The normalized WFR wind profile is derived in a similar way using the friction velocity calculated by the WRF model. Despite the under-prediction by the WRF model it can be seen that the general shape of the wind profile agrees rather well with the measurements. Considering the rather good wind speed prediction, Figs. 3 and 4 , this suggests that the friction velocity in WRF is overpredicted. A reason for this can be that $u_{* 0}$ is a parameterized value in WRF and is an average for the grid box, whereas the measured $u_{* 0}$ is a local value. 


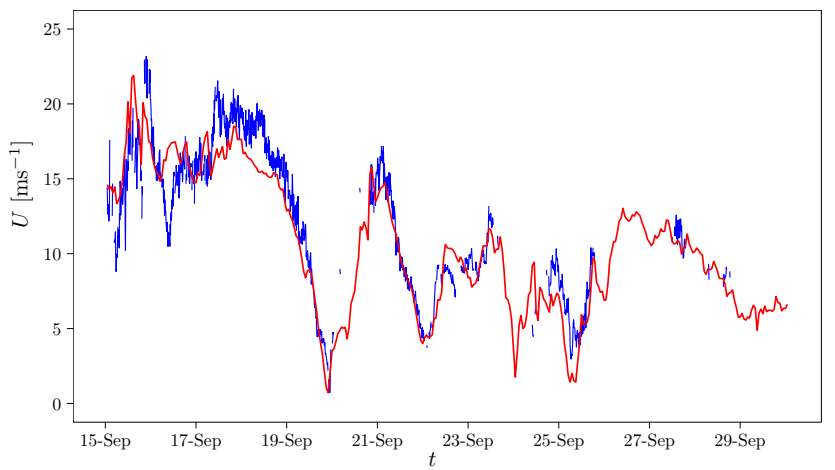

Figure 2. Time series of the wind speed at $100 \mathrm{~m}$ height from the WRF model simulations at the Høvsøre mast (red) and the measurements with the wind lidar (blue) for the period 15-31 September 2010. The lidar measurements are filtered with a Carrier to Noise Ratio (CNR) larger than $-22 \mathrm{~dB}$. The lidar worked well during the whole period, the missing measurements are caused by the filtering.

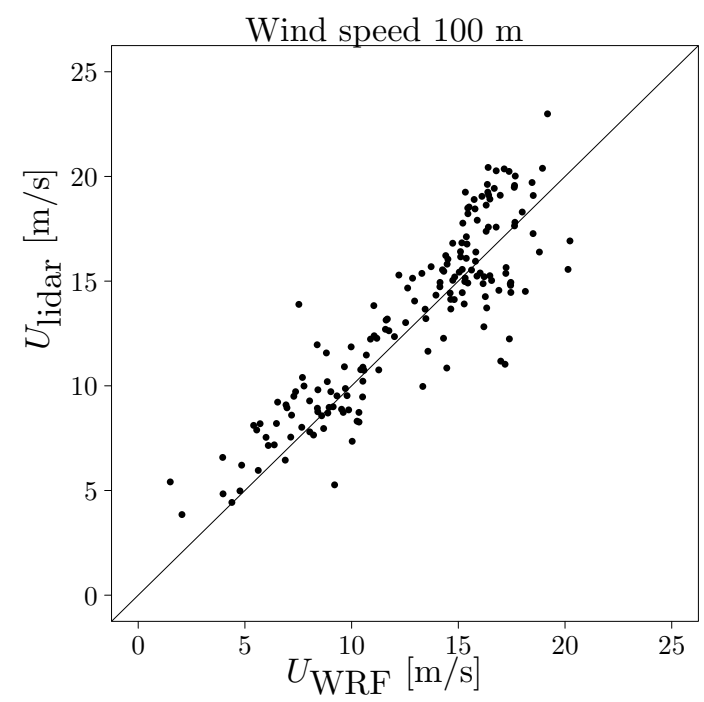

Figure 3. Comparison of the prediction of the wind speed from the simulation by the WRF model and measurements from the wind lidar at $100 \mathrm{~m}$.

\subsection{Effect of stability}

Whereas Fig. 5 represents a composite for all stabilities of the normalized wind speed profile, the variability of the wind profile with atmospheric stability is investigated in this section. The measured wind profiles are divided into stability classes according to the Obukhov length, $L$, Table 1 . The Obukhov length is derived from sonic co-variance measurements of turbulence at $20 \mathrm{~m}$ height at the meteorological mast. For the WRF model, it is derived from the modelled heat flux, friction velocity and temperature.

Figure 6 shows the normalized wind speed profiles sorted into stability classes. The wind profiles order as expected from surface layer theory with the most unstable profile to the

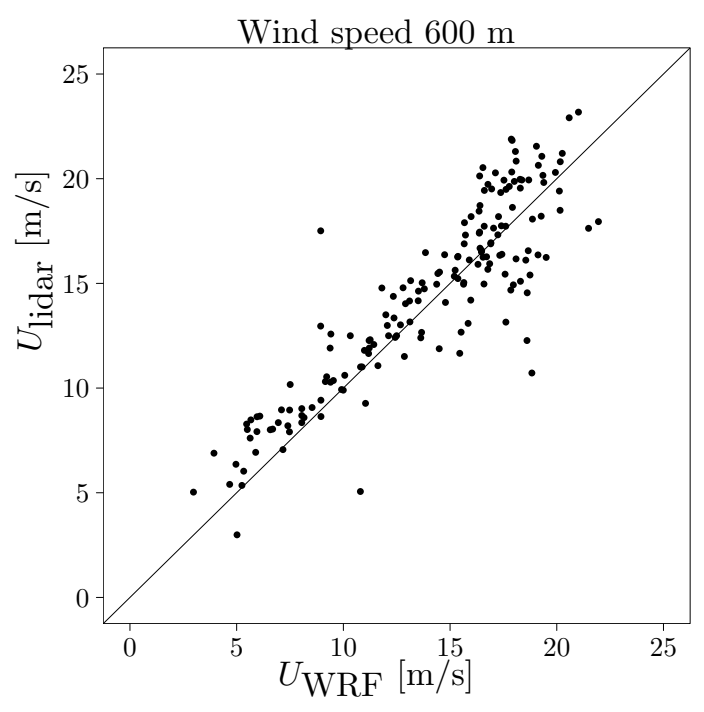

Figure 4. Comparison of the prediction of the wind speed from the simulation by the WRF model and measurements from the wind lidar at $600 \mathrm{~m}$.

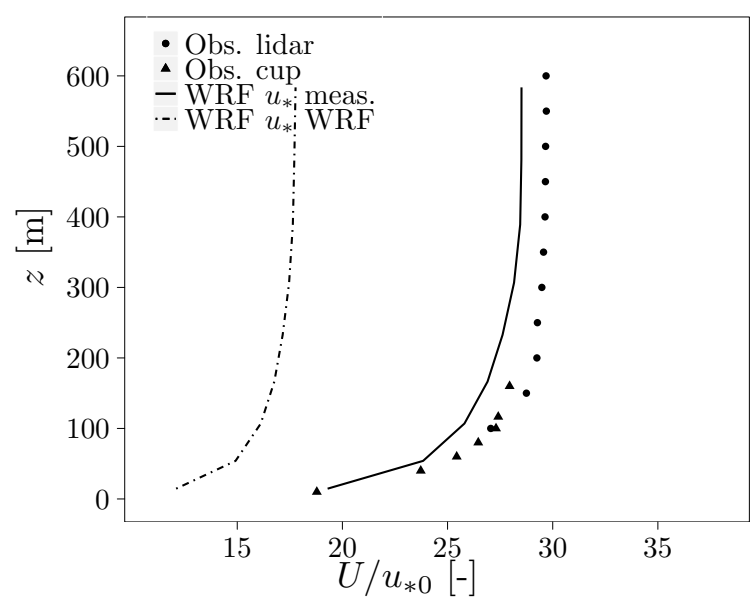

Figure 5. Normalized mean wind speed profile for the entire period, the full line shows the WRF simulations normalized with the observed $u_{* 0}$ and the dashed dotted line with the modelled $u_{* 0}$, the triangles are cup anemometer measurements at the mast and the dots are wind lidar measurements.

left, having the smallest wind speed gradient, and the stable wind profiles to the right with larger wind speed gradients. For very stable conditions the measured wind speed profile shows a characteristic low level jet at around $200 \mathrm{~m}$ height. It is also characteristic for several of the measured profiles that above $500 \mathrm{~m}$ the normalized wind speed decreases slightly with height, which suggest that the atmosphere is baroclinic and not barotropic as assumed in traditional wind profile parameterizations such as Blackadar (1962). Future attempts will be done in order to estimate the baroclinicity shear $S$ :

$S=\left(\frac{d U_{\mathrm{g}}}{d z}\right) \frac{\kappa h}{u_{* 0}}$ 
Table 1. The stability classes according to Obukhov length, $L$.

\begin{tabular}{lllc}
\hline Nr. & Stability class name & Obukhov length interval $[\mathrm{m}]$ & \# of obs. \\
\hline 1 & Unstable (u) & $-100 \geq L \geq-200$ & 10 \\
2 & Near unstable/neutral (nu) & $-200 \geq L \geq-500$ & 17 \\
3 & Neutral (n) & $|L| \geq 500$ & 97 \\
4 & Near stable/neutral (ns) & $200 \geq L \geq 500$ & 22 \\
5 & Stable (s) & $50 \geq L \geq 200$ & 17 \\
6 & Very stable (vs) & $10 \geq L \geq 50$ & 8 \\
\hline
\end{tabular}

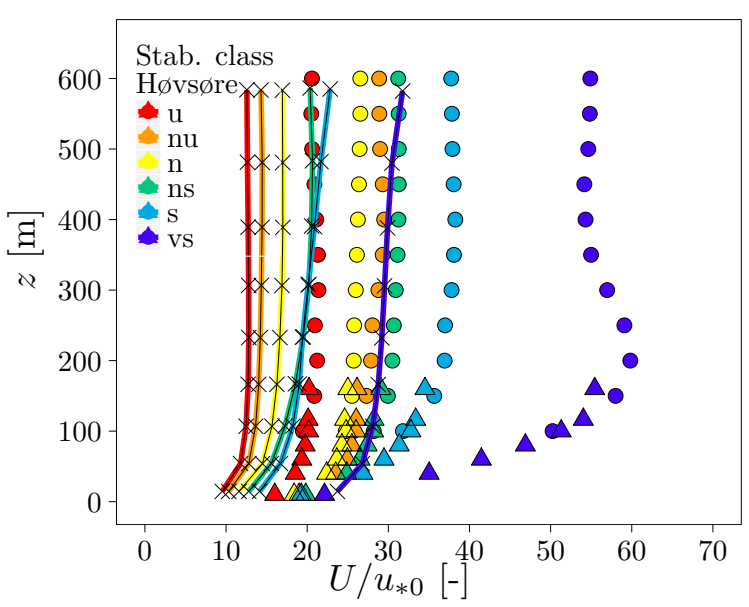

Figure 6. Profiles of normalized wind speeds as function of stability (Table 1). The full lines represent WRF simulations and the symbols measurements as in Fig. 5. The friction velocity that is used to normalize the wind speed for the measurements is taken from the meteorological mast, and for WRF from the simulation.

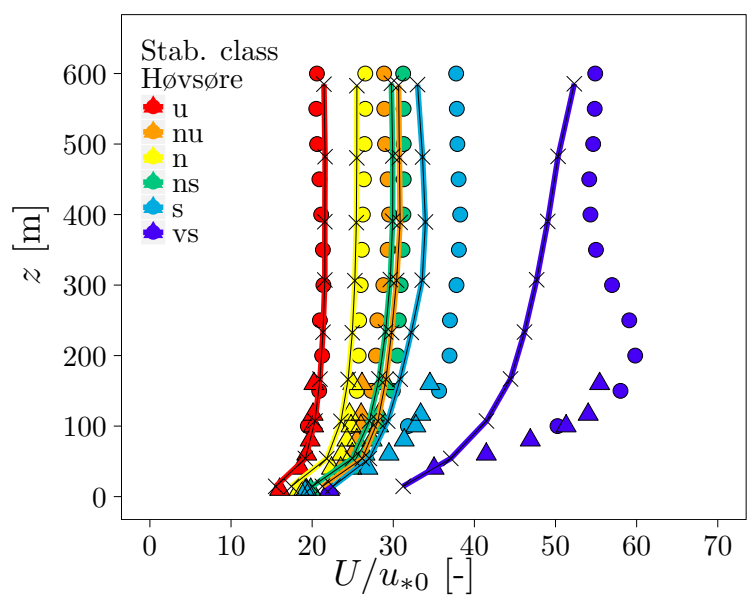

Figure 7. As Fig. 6, except that $u_{* 0}$ is taken from the measurements.

from the gradient of the wind profile in the upper part by use of slightly modified version of the model for the wind profile proposed by Gryning et al. (2007). Here $U_{\mathrm{g}}$ is the geostrophic wind speed at the top of the boundary layer, $k$ is the von Karman constant and $h$ the height of the boundary layer. The effect of baroclinicity is seen in wind profiles for both unstable and stable conditions. Figure 6 also shows wind profiles from the WRF model, normalized with $u_{* 0}$ from WRF and classified according to the modelled $L$ (Table 1). It is seen that the wind profiles vary less with atmospheric stability as compared to the measured wind profiles. This is due to the poor prediction of $u_{*}$ and $L$ in PBL parameterizations of WRF (Pagowski, 2004). Figure 7 shows wind profiles from WRF normalized with the measured $u_{*}$ at Høvsøre and classified according to Table 1 using measured L. Compared to Fig. 6 the agreement between normalized modelled and measured wind profiles improves. However, the model still underpredicts the normalized wind profile for stable conditions. It is interesting to note that although the stability dependence on the wind profiles is poorly modelled in this setup of WRF, it was concluded in Sect. 3.2 that the averaged wind profile agrees rather well. This suggests that the applied configuration of the WRF model can be used to derive the climatological mean wind profile but not the variability around the mean value. Looking at the wind profile from the perspective of a Weibull distribution, the WRF model is expected to predict the scaling parameter $A$ rather well, but not the shape parameter $k$ for the wind profile.

\section{Conclusions}

From recent new observations of the mean wind profile from the ground and up to $600 \mathrm{~m}$ height with a pulsed wind lidar, the wind profiles were derived and compared with WRF model simulations. When averaged over all stability conditions the simulated mean wind profile agrees well with the measurements, although the normalized wind profile was underpredicted by WRF. When the normalized wind profiles were sorted in atmospheric stability classes the WRF model simulations of the normalized wind profiles showed less variability with atmospheric stability as compared to measurements. Use of $u_{* 0}$ from WRF results in a general underestimation of the normalized wind profile, while use of the measured $u_{* 0}$ leads to underprediction for stable conditions only. It was observed that the wind speed decreased with height in the upper part of the wind profile for several of the stability classes. The effect is likely caused by baroclinicity. From the 
perspective of representing the wind profile as a the Weibull distribution, the WRF model simulations in this configuration might be adequate to estimate the profile of the scaling parameter $A$ but caution should be taken with respect to the shape parameter $k$.

Acknowledgements. Contributing to this effort are the Danish Research Agency Strategic Research Council (Sagsnr. 2104-080025) "Tall wind project" and the EU FP7-People-IEF VSABLA (PIEF-GA-2009-237471). It is also related to COST Action ES1002 (WIRE).

Edited by: L. Wald

Reviewed by: two anonymous referees

\section{SC $\mid$ nat $\$$ The publication of this article is sponsored by the Swiss Academy of Sciences.}

\section{References}

Blackadar, A.: The vertical distribution of wind and turbulent exchange in a neutral atmosphere, J. Geophys. Res., 67, 30953102, 1962.

Chen, F. and Dudhia, J.: Coupling an advanced land surfacehydrology model with the Penn State-NCAR MM5 modeling system. Part I: Model implementation and sensitivity, Mon. Weather Rev., 129, 569-585, 2001.

Draxl, C., Hahmann, A., Peña, A., Nissen, J., and Giebel, G.: Validation of boundary-layer winds from WRF mesoscale forecasts with applications to wind energy forecasting, in: 19th Symposium on Boundary Layers and Turbulence, Keystone, Colorado, Paper 1B.1, 7 pp., 2010.
Gryning, S., Batchvarova, E., Brümmer, B., Jørgensen, H., and Larsen, S.: On the extension of the wind profile over homogeneous terrain beyond the surface boundary layer, Bound.-Lay. Meteorol., 124, 251-268, 2007.

Gryning, S., Batchvarova, E., Quante, M., and Matthias, V.: Evaluation of vertical profiles in mesoscale meteorological models based on observations for the COST728 study of winter 2003 PM episodes in Europe, in: Air Pollution Modeling and its Application, edited by: Steyn, D. and Trini-Casteli, S., Springer Science+Business Media B.V, Dordrecht, The Netherlands, in print, 2011.

Holtslag, A.: Estimates of diabatic wind speed profiles from nearsurface weather observations, Bound.-Lay. Meteorol., 29, 225250, 1984.

Hong, S., Noh, Y., and Dudhia, J.: A new vertical diffusion package with an explicit treatment of entrainment processes, Mon. Weather Rev., 134, 2318-2341, 2006.

Pagowski, M.: Some comments on PBL parameterizations in WRF, in: The Joint WRF/MM5 Users' Workshop, Boulder, CO, 1.13, 9 pp., 2004.

Peña, A., Gryning, S., and Hasager, C.: Comparing mixing-length models of the diabatic wind profile over homogeneous terrain, Theor. Appl. Climatol., 100, 325-335, 2010.

Skamarock, W., Klemp, J., Dudhia, J., Gill, D., Barker, D., Duda, M., Huang, X., Wang, W., and Powers, J.: A description of the Advanced Research WRF version 3, Technical Note TN4751STR, NCAR, 2008.

Thompson, G., Rasmussen, R., and Manning, K.: Explicit Forecasts of Winter Precipitation Using an Improved Bulk Microphysics Scheme. Part I: Description and Sensitivity Analysis, Mon. Weather Rev., 132, 519-542, 2004. 